\title{
A PARAMETRIC STUDY OF X AND V BRACING INDUSTRIAL STEEL STRUCTURE
}

\author{
Veera Shobana . $\mathbf{R}^{\mathbf{1}}$, Vijaya Sarathy. $\mathbf{R}^{\mathbf{2}}$, Jose Ravindra Raj. $\mathbf{B}^{\mathbf{3}}$ \\ ${ }^{1}$ M.Tech Student, Department of Civil Enginerring, Prist University, Trichy-Thanjavur Highway, Thanjavur, India \\ ${ }^{2}$ Asst. Professor, Department of Civil Enginerring, Prist University, Trichy-Thanjavur Highway, Thanjavur, India \\ ${ }^{3}$ Asst. Professor, Department of Civil Enginerring, Prist University, Trichy-Thanjavur Highway, Thanjavur, India
}

\begin{abstract}
Severe earthquakes have an extremely low probability of occurrence during a structures life. If the earthquakes to be resisted by the structure elastically, it would require an expensive lateral load resisting system, which is not warranty. The structure may lose its aesthetic and functionality due to minor tremors and needs repairs; it will be a very unfavourable design. In addition to earthquake forces there may be wind or any vibrations which induce lateral loads in a structure. In our work we have taken only the earthquake load to find a system which balances the lateral loads and minimizes the displacements of the floors. With the literature review, it was founded that bracing in a structural system reduces the story drift and reduces the lateral force effect. To examine the performance of the bracings, bracing types like $X$ and $V$ bracings are considered and an analysis is performed in ETABS software. The results are studied, discussed and concluded for the best bracing system among both in our project.
\end{abstract}

Keywords: Bracings, Time - History method

\section{INTRODUCTION}

Structures are usually designed for gravity loads and checked for earthquake loading. In conformity with the design philosophies, there are two steps for this check- the first ensures elastic response under moderate earthquakes and the second ensures that collapse is precluded under severe earthquakes. Due to the uncertainties helping in predicting the inelastic response, the next check may be dispensed with, by facilitating energy dissipation capacity and adequate ductility. In this study, the various methods of performing these checks are described. The factors, which favors earthquake resistant design are, the location of the structure geographically in the soil and foundation condition, structural importance, the dynamic parameters of the structure like the natural periods and the properties of the structure such as ductility stiffness, , and energy dissipation strength capacity,. Directly or indirectly these factors are considered in all the methods of analysis.

This study is made with the following objectives

a. To understand the modelling of buildings braced with conventional concentric braced.

b. To perform the parametric study of bracing system's effectiveness with respect to response parameters: roof displacement and natural time period,

c. To study and determine the effect of aspect ratio of braced steel buildings to minimize the structural damage.

d. To investigate and propose the new and innovative configuration of bracings to control response parameters.
2) Bay width $=3.048 \mathrm{~m} \mathrm{c} / \mathrm{c}$.

3) Number of spans $=5$.

4) Number of bays $=7$.

5) Ceiling height $=5 \mathrm{~m}$ above floor level.

6) Type : Residential building

7) Sections: As per IS4923

8) Beams - RHS $300 \times 200 \times 12$

9) Columns - RHS $300 \times 200 \times 12$

10) Bracings - SHS $250 \times 250 \times 12$

11) Number of floors $-G+3$

Our ETABS model was drawn in Auto CAD 2014 and exported to SAP. The line diagram of the Auto CAD is imported to SAP 2000. In importing, care must be taken in setting the units. Auto CAD units much match the ETABS units. Line diagram is modeled in metre units, so the import unit also will be set as metre units.

Modelling of the structure in the ETABS offers various levels of sophistication and scrutiny. In ETABS various commands for modelling the different elements of the structure can be made. The elements of the braced frame were modelled in the ETABS as per the modeling procedure discussed previously. The modelling of elements of the frame and bracings can be done with very much sophistication.

\section{MODELLING}

Specifications of the building

1) $\mathrm{Span}=8.024 \mathrm{~m} \mathrm{c} / \mathrm{c}$. 


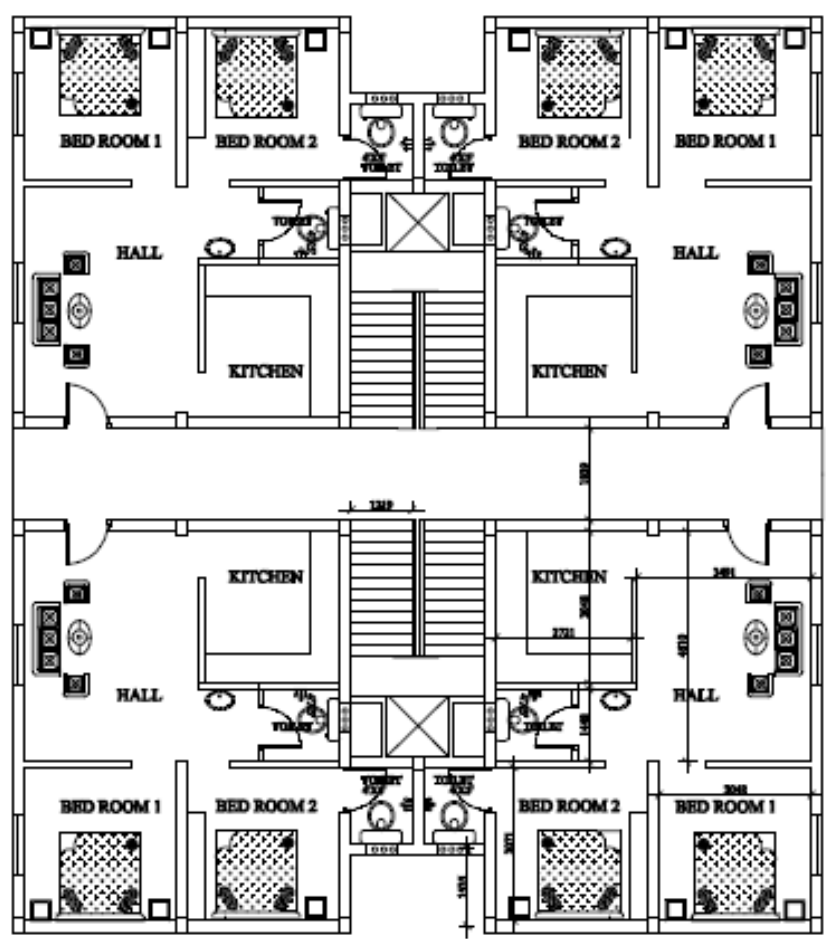

Fig -1: Plan of the structure

Effective damping - 5\%

Type of motion - Transient

$\square$ Combination of modes - absolute SRSS

$\square$ Design code - IS1893-2002

$\square$ Soil type - Hard (fixed support)

$\square$ Methods to use when hinged drop load - Apply local redistribution

$\square$ Damping considered - constant for all modes

$\square$ Method for modal analysis - Eigen Vectors

$\square$ Number of modes considered -12

\subsection{Material Property}

Steel

Yield strength: $250 \mathrm{MPa}$

Modulus of Elasticity: 210Mpa

Poisson's ratio: 0.3

\subsection{Models Analysed}

Our study is a parametric study of a normal structure with a general configuration with two models of the same building with the different bracing types. For reference, we shall take the short forms NB for normal building, $\mathrm{XB}$ for $\mathrm{X}$ braced building and IVB for inverted V brace building. The figures of those structures are noted in fig 2 .

\section{LOADING IN STRUCTURE}

DL - load from structural elements - as per IS 875 Part 1

LL - load from - as per IS 875 Part 2

EQ L - As per IS 1983 - 2002

\subsection{Models Earthquake Load Calculation (EQL)}

Seismic motion consists of horizontal and vertical ground motions, having a much smaller magnitude. With this, the factor of safety provided against

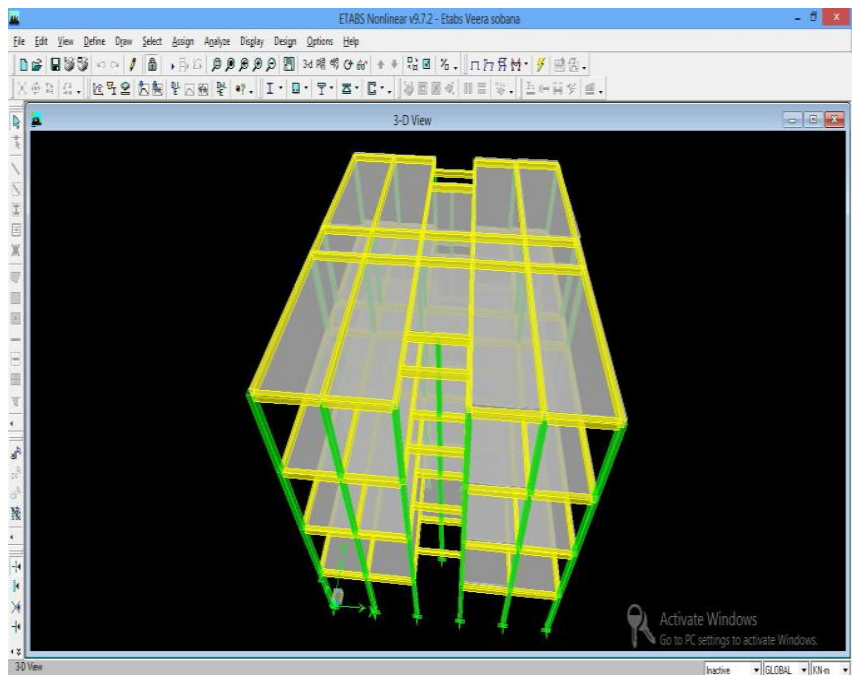

Fig -2 a: Normal Building (NB)

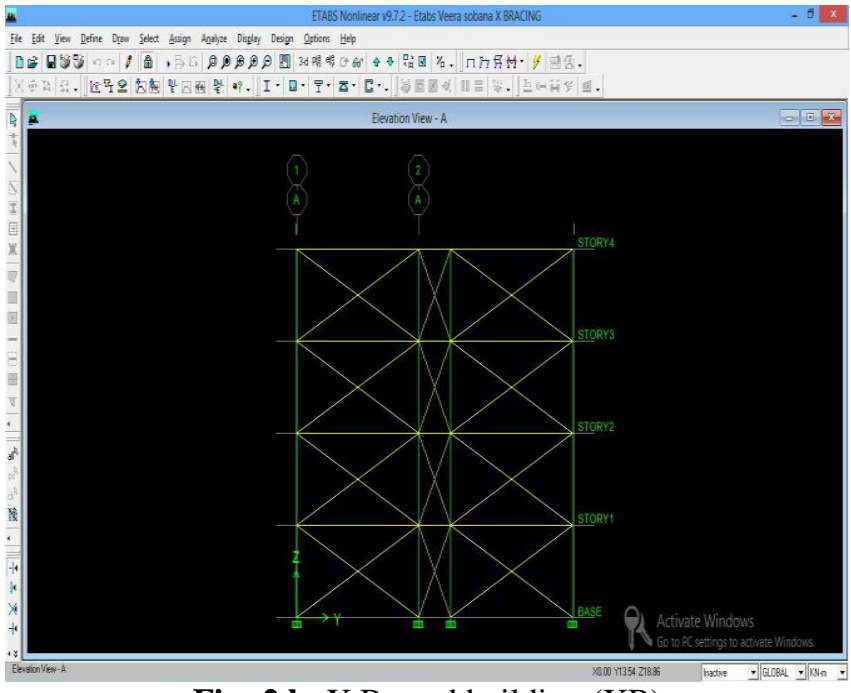

Fig -2 b: X Braced building (XB)

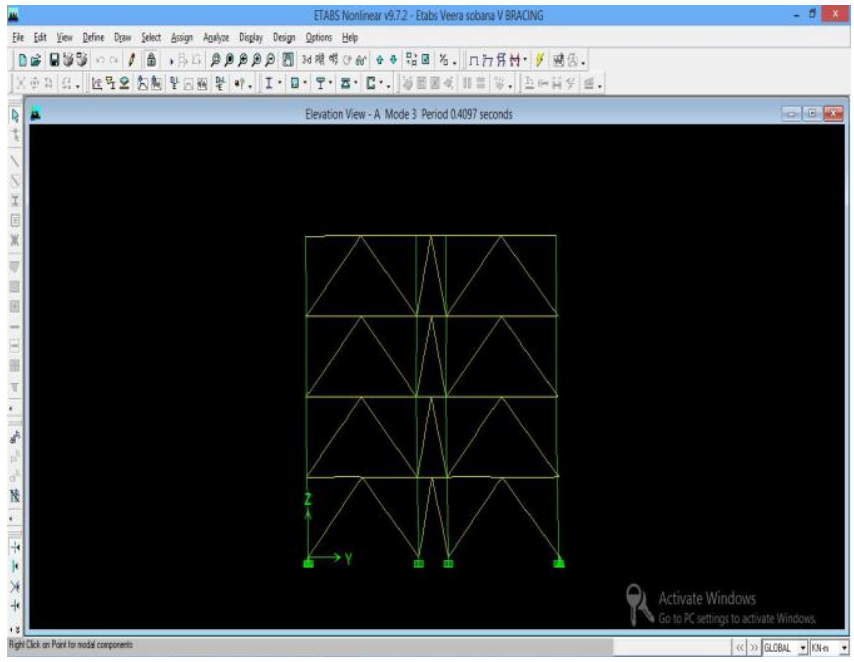

Fig -2 c: Inverted V brace building (IVB) 
Gravity loads usually can accommodate additional forces due to vertical acceleration due to earthquakes. therefore, the horizontal motion in ground causes the most significant effect on the structure by shaking the foundation front and back. The mass of building resists this motion by setting up inertia forces throughout the structure. Earthquake load is induced as acceleration by Time - History method (Th). India's maximum earthquake Th Buij's acceleration is given as EQ acceleration in $\mathrm{X}$ and $\mathrm{Y}$ directions. Fig 3 shows the Th of Buij.

\subsection{Load Combinations}

\begin{tabular}{|l|l|}
\hline \multirow{2}{*}{ SI No } & IS 800 - 2007 - TABLE 4 \\
\cline { 2 - 2 } & Limit State of Strength \\
\hline 1 & $1.5 \mathrm{DL}+1.05 \mathrm{IL}$ \\
\hline 2 & $1.2 \mathrm{DL}+1.05 \mathrm{IL}+1.2 \mathrm{EQX}$ \\
\hline 3 & $1.2 \mathrm{DL}+1.05 \mathrm{IL}+1.2 \mathrm{EQY}$ \\
\hline 4 & $1.3(\mathrm{DL}+\mathrm{LL}+\mathrm{EQX})$ \\
\hline 5 & $1.3(\mathrm{DL}+\mathrm{LL}-\mathrm{EQX})$ \\
\hline 6 & $1.3(\mathrm{DL}+\mathrm{LL}+\mathrm{EQY})$ \\
\hline 7 & $1.3(\mathrm{DL}+\mathrm{LL}-\mathrm{EQY})$ \\
\hline
\end{tabular}

\begin{tabular}{|l|l|}
\hline SI No & IS 1893 - 2002 - 6.3.1.1 \\
\hline 10 & 1.7 ( DL.+LL ) \\
\hline 11 & 1.7 ( DL+EQX) \\
\hline 12 & 1.7 ( DL+EQY) \\
\hline 13 & $1.7($ DL-EQX) \\
\hline 14 & $1.7($ DL-EQY) \\
\hline 15 & 1.3 (DL+LL+EQX) \\
\hline 16 & 1.3 (DL+LL-EQX) \\
\hline 17 & 1.3 (DL+LL+EQY) \\
\hline 18 & 1.3 (DL+LL-EQY) \\
\hline
\end{tabular}

\begin{tabular}{|l|l|}
\hline SI No & Individual Cases \\
\hline 21 & Dead load \\
\hline 22 & Imposed load \\
\hline 23 & Earthquake load in X \\
\hline 24 & Earthquake load in Y \\
\hline 25 & Model \\
\hline
\end{tabular}

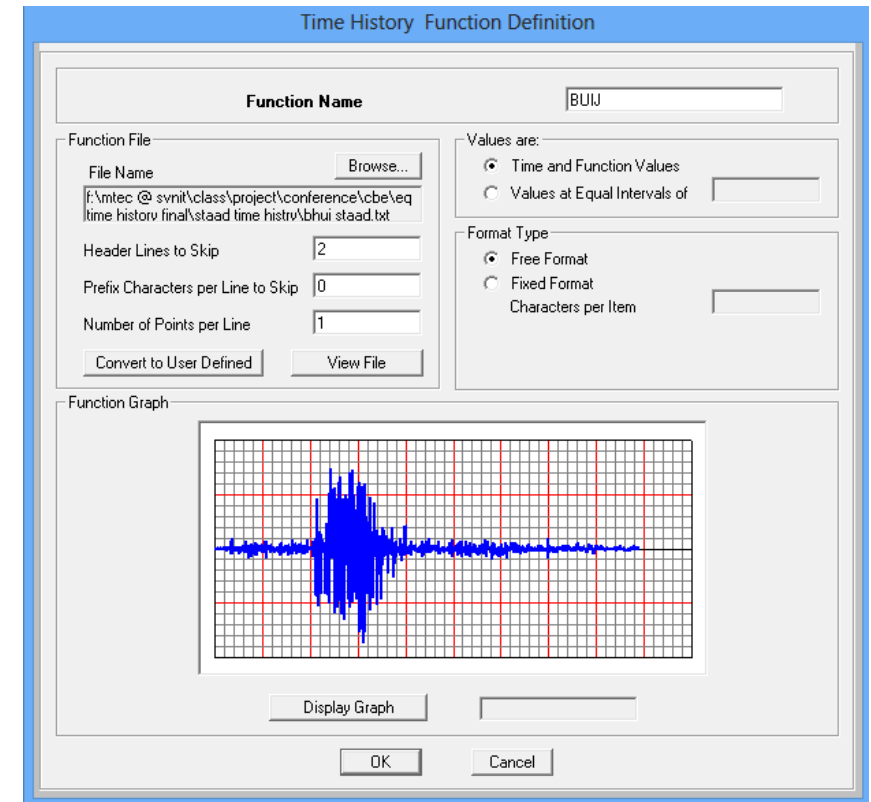

Fig 3 Th of Buij.

The reference number should be shown in square bracket [1]. However the authors name can be used along with the reference number in the running text. The order of the reference is in the running text should match with the list of references at the end of the paper.

Eg1: As per Kong, the density of $X$ increases with $Y$ [9].

$\mathrm{Eg}$ 2: It is reported that $\mathrm{X}$ increase with $\mathrm{Y}$ [45].

\section{RESULTS AND DISCUSSION}

\subsection{Displacement Analysis}

The displacement of a single column is analyses at its floor level and the results are tabulated in the table 2 . In joint 114 maximum displacements were seen which is at roof level, for load combinations. Table 2 shows the displacement of an exterior column at various floor levels. In the case of blast load, maximum displacement in horizontal plane is founded as $138.1 \mathrm{~mm}$. Chart 1 shows the comparison of joint displacement for all models.

Table 2 Joint Displacement

\begin{tabular}{|l|l|l|l|l|l|}
\hline Floor & & $\begin{array}{l}\text { Joint } \\
\text { ID }\end{array}$ & $\begin{array}{l}\text { Un } \\
\text { Braced }\end{array}$ & $\begin{array}{l}\text { V } \\
\text { Braced }\end{array}$ & X Braced \\
\hline Roof & & 114 & 138.1 & 109.154 & 92.57 \\
\hline Third & 89 & 76.59 & 65.87 & 49.67 \\
\hline Second & 66 & 55.4 & 40.7 & 16.105 \\
\hline First & 42 & 29.46 & 21.88 & 2.87 \\
\hline Ground & 21 & 0 & 0 & 0 \\
\hline
\end{tabular}




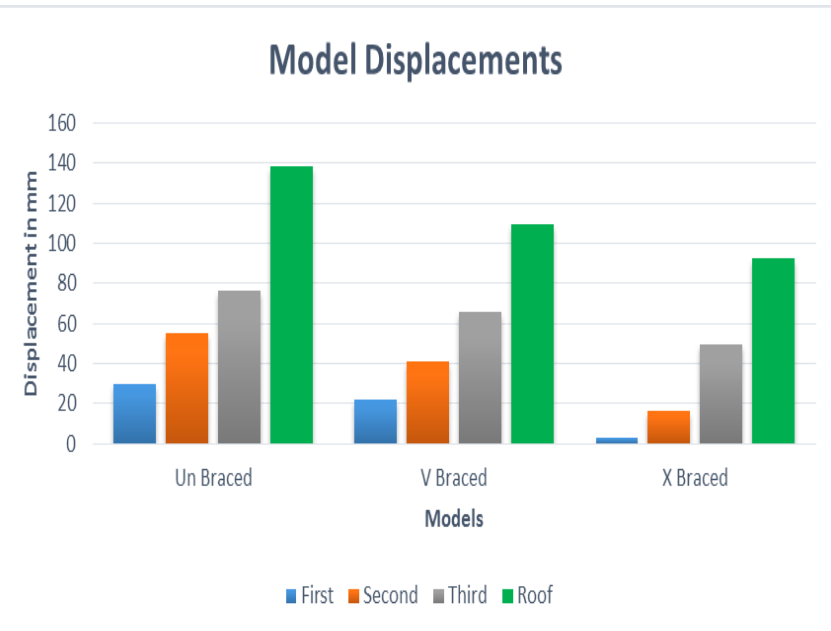

Chart 1: Comparative chart for displacement

From chart 1, it is clear that structure with $\mathrm{X}$ bracing has less deflection when compared to other models. At first floor level, NB has displacement of 9.26 times more than $\mathrm{XB}$ and IVB has 6.62 times more than XB. The same scenario is seen in second, third and roof level also. NB is 2.43 times more in second floor and, 54.19\%, $49.18 \%$ more in third floor and roof level respectively, when compared with XB. IVB is 1.52 has 1.52 times, 0.32times, 0.17 times more displacement than $\mathrm{XB}$ in second, third floors and roof level, respectively. Figure $6.3-6.5$, shows the ETABS window of models NB, IVB and XB.

\subsection{Story Drift}

Story drift is an important parameter, in earthquake analysis. Base shear at ever floor induces movement in each floor, but due to the slab's stiffness, the deformation in floor level is reduced. But due to inverse pendulum effect of structure, relative displacements are observed in the floor levels. This is known as story drift. Our structures performance for various brace configuration is tabulated in chart 2 .

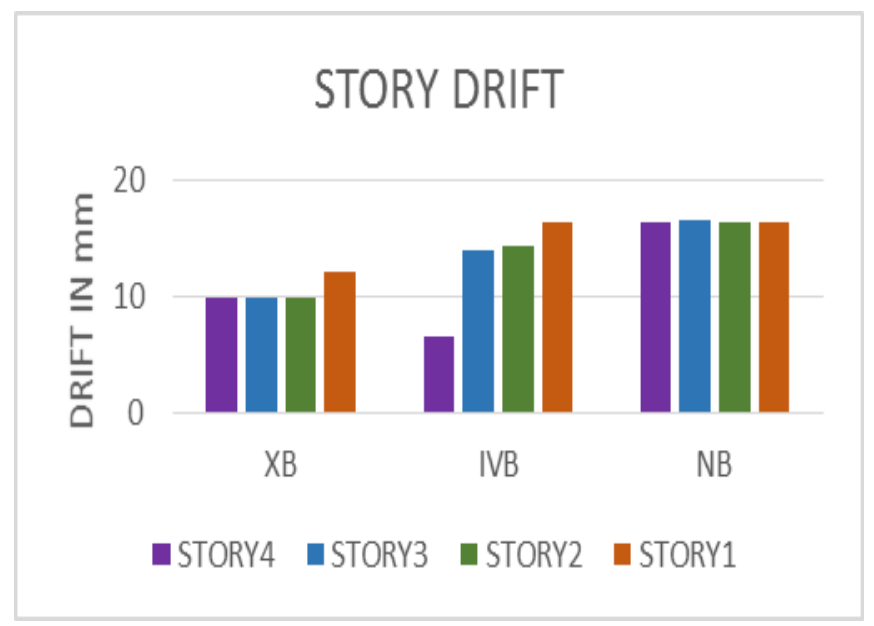

Chart 2: Story drift of all models

While considering the chart 2 , story drift of our structure is compared and the performance of each structure is easily understood. In all story levels, the performance of $\mathrm{XB}$ is founded to be much less than other two models. XB Drift is
$66 \%$ less than NB in roof level and second, third floor levels. At first floor level XB is $36 \%$ less than of NB's drift. Inverted $\mathrm{V}$ bracing models has a variable increase in of drift of XB. IVB has 1.4times, 0.46times and 0.36times less than the normal building.

\subsection{Axial Force Analysis}

Due of bracing, axial force in members may reduce considerably. This can be studied and the bracing which takes much force can be identified. Maximum axial forces are tabulated in table 6.3 for Norman Building, Inverted V Braced building and $\mathrm{X}$ braced Building.

Table 3 Axial force analysis

\begin{tabular}{|l|l|l|l|}
\hline Model & $\begin{array}{l}\text { Member } \\
\text { ID }\end{array}$ & $\begin{array}{l}\text { Load } \\
\text { Combination }\end{array}$ & $\begin{array}{l}\text { Force in } \\
\text { kN }\end{array}$ \\
\hline Tension & \multicolumn{5}{|l|}{} \\
\hline XB & D12 & COMB7 & 41.23 \\
\hline IVB & D50 & COMB6 & 73.1 \\
\hline Normal D54 & COMB6 & 152.84 \\
\hline Compression & 185.5 \\
\hline XB & D16 & COMB4 & 192.69 \\
\hline IVB & D17 & COMB4 & 221.971 \\
\hline Normal D17 & COMB6 &
\end{tabular}

Tension and compressions forces are induced while a lateral load is experienced by the structural members. as a result of inertial force, the structure will return to its original position, by which alternation in stresses gets induced in a structure. In our models the maximum of tensile and compressive forces are compares by chart -3 . For tension force, the structure modelled with XB has less quantity of axial force. This is due to the force balance between the other bracing elements. Joint may have tension and compression members.

\section{Axial force of members}

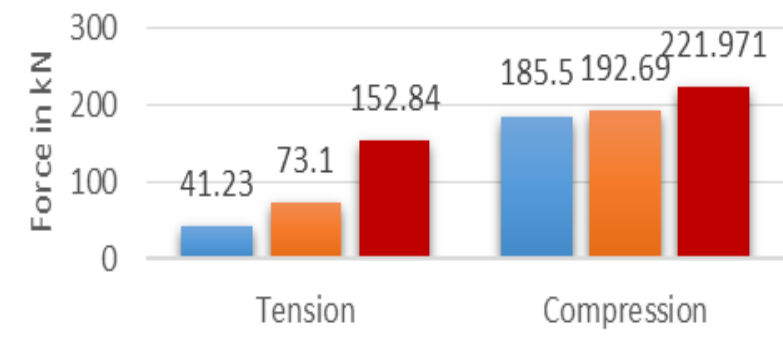

Axial force

\section{-XB IVB - Normal}

\section{Chart -3: Axial force}

Tension is balanced by compression member at that joint. $\mathrm{XB}$ structure has joints consist of tension and compression members. As said early, tension and compression gets balanced in a joint in this XB structure. Therefore some 
additional force other than this force balance is experienced in the structure. So XB is considered as the structure with good bracing configuration.

\section{CONCLUSION}

Based on the results and observation, following conclusions are drawn.

1. All bracings configuration can be used to control the response of roof displacement.

2. Rating of bracing configurations towards the effectiveness of roof displacement control is XB and IVB

3. While, axial force is considered, structure with $\mathrm{XB}$ performs well by balancing the force.

4. Story drift is less in XB structure, where as IVB and NB's drift were more.

Considering all the above points, it shall be concluded to that to minimizing displacement, and increase axial load carrying capacity, $\mathrm{X}$ bracing in a structure shows good performance. But when $\mathrm{X}$ bracings are used in a structure, the openings shall be location accordingly. Other wises the bracings may spoil the elevation of the structure.

\section{REFERENCES}

[1]. Ballio G and Castiglioni C, (1994), Seismic behavior of steel sections', Jnl of Construct. And Steel Research.

[2]. Bertero V and Popov E, (1965), Effect of large alternating strains on steel beams', ASCE. ST1.

[3]. Breneau M and Uang, (1998), Ductile design of Steel Structures', McGraw Hill, New York.

[4]. AISC,(1997), Seismic Provisions for Structural Steel Buildings'.

[5]. AISC-341 (2006a), Seismic provisions for structural steel buildingsll, American institute of steel construction, ANSI/AISC 341. Chicago, USA

[6]. Calado L et al, (1998), Behaviour of steel beam-tocolumn joints under cyclic reversal loading: An experimental study', in Stability and Ductility of Steel Structures, Ed. by Usami and Itoh, Elsevier, London.

[7]. Clough R W and Penzien J,( 1993), Dynamics of Structures', McGraw Hill, New York.

[8]. Clough R W and penzien J, (1993), Dynamics of structurell, McGraw-Hill, 2ND Edition.

[9]. Cosenza E and Manfreidi G, (1992), Seismic analysis of degrading models by means of damage functions concept', in Nonlinear Seismic Analysis of Reinforced Concrete Structures, Ed. by Fajfar P and Krawinkler H, Elsevier Applied Science.

\section{BIOGRAPHIES}

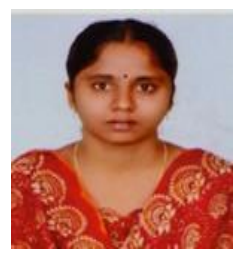

Veera shobana .R is a M.Tech Student at PRIST University, Thanjavur, and his field of interest is in Analysis of structures.

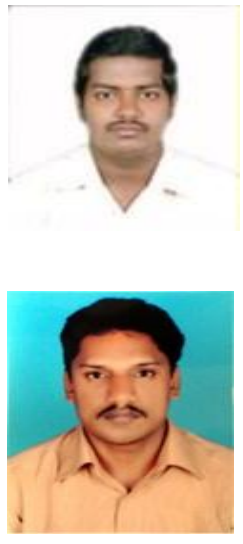

Mr. Vijaya Sarathy.R, is an Asst. Professor, in PRIST University, Thanjavur, his field of interest is in steel structures and concrete technology.

Mr. Jose Ravindra raj.B, is an Asst. Professor, in Prist University, Thanjavur, his field of of interest is in structural analysis, steel structures. 